\title{
Interfaces entre educação profissional e pedagogia da alternância
}

\section{Interface between education and professional alternation pedagogy}

\section{Interfaces entre educación profesional y pedagogía de la alternancia}

\author{
Ramofly Bicalho ${ }^{1}$ \\ Jean Rubyo Oliveira²
}

DOI: http://dx.doi.org/10.20435/serie-estudos.v22i46.967

\begin{abstract}
Resumo: Este artigo aborda as possíveis interfaces entre educação profissional e pedagogia da alternância no curso técnico de agropecuária, do Instituto Federal do Espírito Santo (IFES), Campus Barra de São Francisco. Consultamos documentos produzidos pelo IFES, Universidades, Ministério da Educação e Movimentos Sociais. Acreditamos que a presença do IFES na comunidade pode fortalecer as famílias camponesas e realidades do entorno, garantindo a qualidade da educação, direitos e especificidades dessa população, suas histórias de vida, identidades, memórias e valorização cultural. Nesse processo de pesquisa e construção histórica, prevaleceu o respeito às diferenças e a valorização da identidade cultural dos atores envolvidos, propondo uma educação inclusiva, questionadora, democrática e por alternância, nas instituições de ensino federalizadas. As interfaces entre educação profissional e pedagogia da alternância são reais, considerando as possibilidades políticas, pedagógicas e sociais presente nos cursos técnicos do IFES, Campus Barra de São Francisco.
\end{abstract}

Palavras-chave: educação profissional; pedagogia da alternância; agropecuária.

\begin{abstract}
This article discusses the possible interfaces between education and alternation pedagogy in the technical progress of agriculture, the Federal Institute of the Espírito Santo (IFES), Campus Barra de São Francisco. Consult documents produced by IFES, Universities, Ministry of Education and Social Movements. We believe that the IFES presence in the community can strengthen peasant families and the surrounding realities, ensuring the quality of education, rights and specificities of this population, their life histories, identities, memories and cultural appreciation. In this research and historical construction process prevailed respect for differences and appreciation of the cultural identity of the players involved, proposing an inclusive education, questioning, and democratic alternation, in federalized educational institutions. The interfaces between education and pedagogy of alternation are real, considering the political, educational and social opportunities present in technical courses of IFES, Campus Barra de São Francisco.
\end{abstract}

Key words: professional education; pedagogy of alternation; agriculture.

\footnotetext{
${ }^{1}$ Universidade Federal Rural do Rio de Janeiro (UFRRJ), Seropédica, Rio de Janeiro, Brasil.

${ }^{2}$ Instituto Federal do Espírito Santo (IFES), Barra de São Francisco, Espírito Santo, Brasil.
} 
Resumen: Este artículo aborda las posibles interfaces entre educación profesional y pedagogía de la alternancia en el curso técnico de agropecuaria, del Instituto Federal de Espírito Santo (IFES), Campus Barra de San Francisco. Consultamos documentos producidos por el IFES, Universidades, Ministerio de Educación y Movimientos Sociales. Creemos que la presencia del IFES en la comunidad puede fortalecer a las familias campesinas y realidades del entorno, garantizando la calidad de la educación, derechos y especificidades de esa población, sus historias de vida, identidades, memorias y valorización cultural. En este proceso de investigación y construcción histórica, prevaleció el respeto a las diferencias y la valorización de la identidad cultural de los actores involucrados, proponiendo una educación inclusiva, cuestionadora, democrática y por alternancia, en las instituciones de enseñanza federalizadas. Las interfaces entre educación profesional y pedagogía de la alternancia son reales, considerando las posibilidades políticas, pedagógicas y sociales presentes en los cursos técnicos del IFES, Campus Barra de San Francisco.

Palabras clave: educación profesional; pedagogía de la alternancia; agropecuaria.

\section{INTRODUÇÃO}

Nossa intenção com este trabalho é divulgar os primeiros resultados da Dissertação de Mestrado em Educação Agrícola: Utilização dos instrumentos pedagógicos da alternância no curso técnico em agropecuária, do Instituto Federal do Espírito Santo (IFES), Campus Barra de São Francisco, realizada no Programa de PósGraduação em Educação Agrícola (PPGEA), da Universidade Federal Rural do Rio de Janeiro (UFRRJ). O objetivo principal foi compreender as possíveis interfaces entre a educação profissional e os instrumentos didáticos e pedagógicos da alternância no curso de agropecuária do IFES, considerando a participação dos sujeitos como seres históricos e culturais.

Na construção dos referenciais teórico-metodológicos, consultamos inúmeros documentos ${ }^{3}$ produzidos pelo Ministério da Educação (MEC), em parceria com os institutos federais, universidades públicas, secretarias municipais de educação e mo-

\footnotetext{
${ }^{3}$ 1) Constituição da República Federativa do Brasil de 1988, Título I, Artigo 3o IV e Seção I - Da Educação, Artigo 206; 2) Lei de Diretrizes e Bases da Educação Nacional (LDB), n. 9.394/96, Artigos, 28, 78, 79; 3) Encontro Nacional de Educadores da Reforma Agrária (ENERA), organizado em 1997, pelos movimentos sociais do campo, em parceria com a Universidade de Brasília (UnB); 4) Programa Nacional de Educação na Reforma Agrária (PRONERA), criado em 1998, junto ao Instituto Nacional de Colonização e Reforma Agrária (INCRA) e o Ministério do Desenvolvimento Agrário (MDA); 5) Resolução do Conselho Nacional de Educação / Conselho Educação Básica- CNE/CEB n. 1, de 3 de abril de 2002 - Diretrizes Operacionais para a Educação Básica das Escolas do Campo; 6) Programa Escola Ativa; 7) ProJovem Campo Saberes da Terra; 8) ProJovem Rural; 9) Resolução n. 4, de 13 de julho de 2010, que define as Diretrizes Curriculares Nacionais Gerais para a Educação Básica e, nela, a educação do campo como modalidade de ensino; 10) Decreto n. 7.352, de 4 de novembro de 2010, que dispõe sobre a política de educação do campo e o Programa Nacional de Educação na Reforma Agrária (PRONERA) e, por último, 11) Programa Nacional de Educação do Campo (PRONACAMPO), lançado no dia 20 de março de 2012.
} 
vimentos sociais do campo, além da nossa participação em reuniões com acesso às atas e aos relatórios. Nesta pesquisa, comparamos e entrecruzamos vozes advindas de diversas fontes documentais e escritas, tendo como principal desafio, entender a possível sintonia entre os instrumentos pedagógicos da alternância e o curso técnico em agropecuária do IFES.

Essas experiências podem contribuir para gestação de embriões de democratização, socialização de poder, superação dos desafios, afirmação de identidades e seres humanos preocupados com o fortalecimento de ambientes coletivos. Existe hoje nos espaços formais e informais da produção do conhecimento, uma urgente necessidade de intervenção, propondo reflexões que tenham por meta problematizar as dificuldades apresentadas quanto às questões teórico-metodológicas e de articulação entre educação profissional e pedagogia de alternância, na perspectiva crítica, dialógica e histórica do saber.

Conhecer os instrumentos da pedagogia da alternância nesta pesquisa foi essencial. Para instituição de ensino, eles apresentam boa funcionalidade, agregando responsabilidades aos educadores, educandos, familiares e comunidade. Por exemplo, os educandos aplicaram, nas propriedades rurais dos seus familiares e vizinhos, conteúdos programáticos relacionados à sustentabilidade local, em sintonia com a produção crítica do conhecimento, em diferentes espaços e tempos de formação.

Reconhecemos os instrumentos didáticos e pedagógicos da alternância, entre outros aspectos, quando os estudantes se apropriam do debate acerca dos diversos tempos de formação: Tempo Escola (TE) e Tempo Comunidade (TC). No TE, aprendem instrumentalizar as técnicas agrícolas, cuidados com a conservação do solo, autonomia, autoformação e interação com os demais sujeitos desse espaço escolar. Os preceitos teóricos desenvolvidos no TE são implementados no TC, como suporte para as culturas desenvolvidas por seus familiares: café, milho, hortaliças, frutas, entre outras. Ou seja, o processo de ensino-aprendizagem defendido pela escola deve ser útil à formação crítica dos estudantes e familiares.

Em sua grande maioria, as instituições de ensino apresentam estruturas curriculares e Projetos Políticos Pedagógicos (PPP) ainda muito conservadores, com aulas $100 \%$ presenciais e pouquíssima flexibilidade em relação aos conteúdos didáticos. Uma grade curricular institucionalizada pela federação, exclusiva de cada curso, com pouca participação dos familiares e comunidade no acompanhamento e desempenho dos estudantes. Acreditamos que a sintonia entre educação profissional e pedagogia da alternância, na perspectiva crítica do saber, se fortalece com 
a participação intensiva dos educadores, educandos e familiares, responsáveis pela educação desses sujeitos. Nessa conjuntura, importante considerar as histórias, memórias, identidades e realidades dos estudantes do campo, seus vínculos com o trabalho coletivo e movimentos sociais.

\section{INSTRUMENTOS UTILIZADOS NA PEDAGOGIA DA ALTERNÂNCIA}

A aplicação dos instrumentos da pedagogia da alternância pelo IFES, Campus Barra de São Francisco, no curso técnico em agropecuária, não utilizou as ferramentas TE e TC. No entanto, de forma interdisciplinar, educadores, educandos, familiares e comunidade utilizaram, a partir de Gimonet (2007), Begnami (2003) e Silva (2006), os seguintes elementos da pedagogia da alternância:

a) Plano de Estudo - constitui o principal instrumento metodológico. É um método de pesquisa participativa, através de questionários. Analisa os vários aspectos da realidade dos estudantes, promovendo relações autênticas entre vida e escola. Através do plano de estudo, as potencialidades da alternância são viabilizadas, enquanto fonte de reflexão. Ele é o instrumento que permite desencadear motivação e compreensão dos significados, políticos e sociais, dos conteúdos curriculares. É o elemento que reúne interrogação e diálogo. Organiza a reflexão e desperta o interesse para aprendizagens dinâmicas. É único e intransferível, pois cada grupo de estudantes, vive situações e interesses distintos, respeitando metodologias próprias de elaboração. Segundo Silva (2006, p. 6):

[...] alternância, enquanto princípio pedagógico, mais que característica de sucessões repetidas de sequências, visa desenvolver na formação de jovens, situações em que o mundo escolar se posiciona em interação com o mundo que o rodeia. Buscando articular universos considerados opostos ou insuficientemente interpenetrados - o mundo da escola e o mundo da vida, a teoria e a prática, o abstrato e o concreto - a alternância coloca em relação diferentes parceiros com identidades, preocupações e lógicas também diferentes: de um lado, a escola e a lógica da transmissão de saberes e, de outro, a família e a lógica da pequena produção agrícola.

b) Conteúdos Vivenciais - são expressões dos conhecimentos extraídos da realidade dos estudantes, através do plano de estudo. São elementos da realidade que o jovem compreendeu com precisão, somado às suas histórias de vida, identidades e memórias. No processo educativo, o ponto maior de reflexão, transformação e produção crítica do conhecimento, acontece na estreita relação entre os aspectos científicos e a realidade de vida dos estudantes. 
c) Temas Geradores - tem como objetivo principal, definir situações de interesses e motivações de educadores e educandos, numa determinada região. Pode interferir na transformação dos sujeitos, individuais e coletivos, considerando as diferentes realidades, ciclos, séries e as seguintes temáticas: água, agricultura familiar, movimentos sociais, alternância, agrotóxicos, sementes transgênicas, entre outros aspectos. Nesse contexto, os temas geradores, demarcados por educadores, educandos, familiares e comunidade, devem dialogar com as disciplinas curriculares, planos de estudos e avaliações.

d) Visita e Viagem de Estudo - tem como função observar, conhecer e comparar as diferentes realidades sociais, políticas e profissionais dos espaços visitados, com ênfase nas realidades vivenciadas pelos estudantes. O destino da viagem de estudo é uma escolha coletiva e tem a função de aprofundar os temas geradores, abordados durante o ano letivo. A interação entre educadores, educandos e familiares é essencial na produção do conhecimento, estudos e pesquisas. Importante ainda registrar os aspectos que envolvem diversão e prazer no ato de aprender com os diferentes sujeitos e realidades.

e) Intervenção e Palestras - estas atividades são muito valorizadas na pedagogia da alternância. Garante o contato dos educadores e educandos com as inúmeras experiências, individuais e coletivas, ligadas aos temas geradores. Na região, uma determinada temática é escolhida e aprofundada, através de rodas de conversas, depoimentos, palestras com educadores, familiares, lideranças de movimentos sociais, sindicalistas, religiosos, agricultores e demais sujeitos envolvidos com os temas geradores, escolhidos coletivamente.

f) Cursinhos - através das atividades teóricas e práticas, os estudantes se apropriam dos conhecimentos assimilados nas disciplinas, desenvolvendo temáticas específicas, a partir das suas reais necessidades. Por exemplo, interessante, na aplicação dos produtos tóxicos, conhecer os seus males, as inúmeras pragas existentes e seu combate. Nessas ocasiões, se faz necessária a presença crítica de profissionais especialistas na área, sinalizando para os benefícios e malefícios agregados aos produtos utilizados.

g) Experiências - caminham juntas, na pedagogia da alternância, as diversas experiências teóricas e práticas vivenciadas pelos estudantes em suas residências, comunidades e espaço escolar. Em casa, o estudante é o protagonista. Ele planeja, executa, acompanha, busca soluções, compara, avalia e relata as atividades, numa estreita parceria com seus familiares. Na escola, o planejamento coletivo é realizado 
por educadores e educandos. As atividades de execução, observação e acompanhamento são realizadas no coletivo dos jovens, valorizando as atividades práticas e os aspectos teóricos.

h) Atividade de Retorno - embora os estudantes estejam diariamente na escola e na sua residência, eles desenvolvem diversas atividades em suas comunidades. Trabalham com temáticas resultante das reflexões e aprofundamentos acerca dos conhecimentos práticos estudados na escola e, em suas comunidades, nas formas de: palestras, cursos e visitas. As atividades de retorno possuem, dentre outras, as seguintes finalidades: desenvolver junto aos estudantes, familiares e comunidade, motivação, compromisso, responsabilidade e autoestima, rompendo com as possíveis dificuldades encontradas no meio em que se vive.

i) Caderno da Realidade - nesse caderno, os estudantes registrarão suas experiências bem sucedidas, fracassos, aplicações do conhecimento, entre outros aspectos que contribuam para aprendizagens significativas, produção crítica e emancipadora do conhecimento. Registra ainda os inúmeros acontecimentos políticos, sociais e culturais, suas reflexões e estudos aprofundados da realidade. É o elemento que permite a sistematização das pesquisas, ideias e ações provocadas pelo plano de estudo. A tendência é que o caderno da realidade, enquanto ferramenta utilizada diariamente, sofra, constantemente, inúmeras adaptações.

j) Convivência - são situações vivenciadas pelos estudantes nos espaços da escola e familiar, tais como: atitudes, relações pessoais e coletivas, capacidade de fazer, comunicar-se, disponibilidade, solidariedade, organização pessoal, liderança, responsabilidade, compromisso, diálogo, respeito, valores e persistência na realização das tarefas. Aqui tomamos o termo convivência com a intenção de aprofundar as questões sociais, culturais e de estudo. A cada semestre, preferencialmente, os aspectos da convivência são analisados, a partir de roteiros subsidiados por temáticas. O estudante faz uma autoavaliação e é avaliado por seus familiares e colegas de classe. Por fim, essas reflexões são trabalhadas coletivamente, em comum acordo, com as turmas.

Considerando os aspectos apresentados acima, entendemos a necessidade de reafirmar e consolidar currículos, metodologias, espaços educativos e formação de professores que se apropriam da pedagogia da alternância. Estudos voltados para prática em sala de aula (SILVA, 2006) propõem novas formas de atuação do professor. Ele passa de transmissor do conhecimento para agente estimulador e incentivador, desenvolvendo práticas reflexivas e emancipadoras do conhecimento. 


\section{EDUCAÇÃO PROFISSIONAL E PEDAGOGIA DE ALTERNÂNCIA}

Com a promulgação do Decreto n. 5.154/04 (BRASIL, 2004a), deu-se origem à "perspectiva de formação com a integração dos conteúdos da educação geral e da formação profissional, considerando a construção do conhecimento pela mediação do trabalho, da ciência e da cultura". Essa formação pode permitir que educadores e educandos conquistem a tão sonhada dignidade, autorrespeito e reconhecimento social, propiciando aprendizagens eficientes, éticas, cidadã e competências laborais imprescindíveis, num mundo do trabalho, cada vez mais competitivo, opressor e em permanente transformação. Nesse sentido, o ingresso e a permanência dos estudantes no ensino médio exige conhecimentos que, certamente, subsidiarão sua formação posterior. Para Frigotto (2006, p. 76) o ensino médio:

[...] concebido como educação básica e articulado ao mundo do trabalho, da cultura e da ciência, constitui-se em direito social e subjetivo e, portanto, vinculado a todas as esferas e dimensões da vida. Trata-se de uma base para o entendimento crítico de como funciona e se constitui a sociedade humana em suas relações sociais e como funciona o mundo da natureza, da qual fazemos parte. Dominar no mais elevado nível de conhecimento estes dois âmbitos é condição prévia para constituir sujeitos emancipados, criativos e leitores críticos da realidade onde vivem e com condições de agir sobre ela. Este domínio também é condição prévia para compreender e poder atuar com as novas bases técnicas- cientificas do processo produtivo.

Entendemos que trabalho, ciência e cultura possuem suas particularidades. São unidades diversas que se complementam. O curso técnico em agropecuária do IFES, Campus Barra de São Francisco, na construção do seu Projeto Político de Curso (PPC), busca as interfaces possíveis entre educação profissional e os instrumentos de implantação da pedagogia da alternância. Esse curso vem produzindo técnicas que considerem os aspectos de aperfeiçoamento das pesquisas e experimentação, a fim de produzir e acumular conhecimentos que contribuam para emancipação dos sujeitos, Frigotto (2006, p. 1) afirma que:

A técnica tende a ser um aperfeiçoamento dentro da mesma linha de processo produtivo, de um determinado estágio técnico; a tecnologia é quando há uma inovação qualitativa; e a ciência é uma forma sistemática de buscar tanto inovações técnicas quanto tecnológicas, mas também se alimenta de processos técnicos e tecnológicos.

Compreendemos que a proposta de ensino técnico em agropecuária, sob as diretrizes da pedagogia da alternância, deve romper com a formação autoritária e 
conservadora dos jovens, valorizando aspectos críticos e emancipadores na produção do conhecimento. A intenção é desafiar-se na construção de propostas pedagógicas que considerem os interesses da juventude, formação integrada e superação da dualidade. Um ensino médio técnico que prepara para o mundo do trabalho e, ao mesmo tempo, para continuidade dos estudos que emancipa os sujeitos. Pacheco (2012, p. 60) destaca que:

[...] o que se quer é que a educação geral se torne parte inseparável da educação profissional em todos os campos em que se dá a preparação para o trabalho: seja nos processos produtivos, seja nos processos educativos, como a formação inicial, o ensino técnico, tecnológico ou superior. Significa que buscamos enfocar o trabalho como princípio educativo, no sentido de superar a dicotomia trabalho manual/trabalho intelectual, de incorporar a dimensão intelectual ao trabalho produtivo, de formar trabalhadores capazes de atuar como dirigentes e cidadãos.

Os desafios são muitos na construção de currículos que integrem os aspectos didáticos, políticos, sociais, culturais e pedagógicos da alternância, na estreita relação com o ensino técnico em agropecuária. Com referência à educação profissional, Frigotto (2006, p. 2) destaca que:

O que acontece com a educação profissional é que na sociedade capitalista a educação tende a ter duas funções: adequar a força de trabalho às funções da economia e produzir ideologicamente e politicamente uma consciência alienada. Desde que o capitalismo surgiu houve o discurso da igualdade em todos os campos, mas na verdade ele só pode existir e prosperar na desigualdade. Então nós vamos ter sistemas duais da educação: um que vai preparar aqueles que vão ser dirigentes, numa escola geral, clássica e longa; e outro pra quem tem pouco tempo pra estudar, pois tem que enfrentar o duro exercício do trabalho.

Entendemos que o ensino técnico pode representar diversas possibilidades de profissionalização, com propostas pedagógicas que contemplem a integração dos campos de saberes. Deve buscar a valorização das diversas habilidades, contexto social, iniciativa, trabalho coletivo e inserção social dos jovens na escola. É nesse contexto que a instrumentalização da pedagogia da alternância, obtém resultados mais eficazes. As políticas públicas de educação profissional e tecnológica contaram, no Decreto n. 2.208/97, com duas concepções: uma ancorada na educação profissional e básica, e outra, nos princípios da educação tecnológica e politécnica. O Decreto 2.208/97 trata do:

[...] Programa de Expansão da Educação Profissional (Proep) e as ações deles decorrentes ficaram conhecidos como a Reforma da Educação Profissional. Nesse 
contexto, o ensino médio retomou em termos legais um sentido puramente propedêutico, enquanto os cursos técnicos, agora obrigatoriamente separados do ensino médio, passaram a ser oferecidos de duas formas: • a concomitante ao ensino médio, em que o estudante pode fazer ao mesmo tempo o ensino médio e um curso técnico, mas com matrículas e currículos distintos, podendo os dois cursos ser realizados na mesma instituição (concomitância interna) ou em diferentes instituições (concomitância externa). - a sequencial ou subsequente, destinada a quem já concluiu o ensino médio.

A regulamentação do Decreto n. 5.154/04 (BRASIL, 2004a) contribuiu para superação dessa dualidade. Ele defende o resgate do ensino integrado, presente na Lei n. 9.394/96 (BRASIL, 1996), em seu artigo 39: "a educação profissional, integrada às diferentes formas de educação, ao trabalho, à ciência e à tecnologia, conduz ao permanente desenvolvimento de aptidões para a vida produtiva". No caso do ensino médio, etapa final da educação básica, essa articulação adquire especificidades quanto à preparação dos estudantes no exercício de profissões com habilidades técnicas, destacado na Lei n. 9.394/96, artigo 36-A e parágrafo único:

[...] o ensino médio, atendida à formação geral do educando, poderá prepará-lo para o exercício de profissões técnicas. Parágrafo Único- A preparação geral para o trabalho e, facultativamente, a habilitação profissional poderão ser desenvolvidas nos próprios estabelecimentos de ensino médio ou em cooperação com instituições especializadas em educação profissional. (BRASIL, 1996).

O artigo 40 da Lei n. 9.394/96 estabelece que: “a educação profissional será desenvolvida em articulação com o ensino regular ou por diferentes estratégias de educação continuada, em instituições especializadas ou no ambiente de trabalho" (BRASIL, 1996). É justamente nessa flexibilidade da legislação que se atribui a funcionalidade e viabilidade da instrumentalização didático-pedagógica da alternância, no Curso Técnico em Agropecuária. Assim, a proposta do ensino técnico federalizado integrado às diretrizes didático-pedagógicas da alternância pode contribuir na formação de jovens para cidadania, apresentando desafios na construção de propostas pedagógicas emancipadoras que contemple os interesses da juventude, e uma formação integrada que supere a dualidade na produção do conhecimento.

A implementação das ferramentas didático-pedagógicas da alternância integradas à educação técnico-profissional pode ser evidenciada através do Decreto $\mathrm{n}$. 5.154/04 e do Parecer n. 39/04 (BRASIL, 2004b). Tais documentos permitem que as instituições de ensino tenham, em suas práticas, currículos que considerem a formação geral e profissional. Numa visão muito complexa, Sacristán (2000, p. 15) afirma 
que: "o currículo é uma práxis antes que um objeto estático emanado de um modelo coerente de pensar a educação ou as aprendizagens necessárias das crianças e dos jovens, que tampouco se esgota na parte explicita do projeto de socialização cultural nas escolas". Nessa perspectiva, o autor evidencia que, na construção e execução das propostas pedagógicas de formação integral, as instituições de ensino devem considerar as relações sociais e culturais de seus estudantes. Segundo Sacristán (2000, p. 17):

O currículo em seu conteúdo e nas formas através das quais se nos apresenta e se apresenta aos professores e aos alunos, é uma opção historicamente configurada, que sedimentou dentro de uma determinada trama cultural, política, social e escolar; está carregado, portanto, de valores e pressupostos que é preciso decifrar. Tarefa a cumprir tanto a partir de um nível de análise político-social quanto a partir do ponto de vista de sua instrumentação "mais" técnica, descobrindo os mecanismos que operam em seu desenvolvimento dentro dos campos escolares.

Defendemos a necessidade de integração dos saberes na construção do currículo da educação profissional integrado à educação básica e aos princípios da pedagogia da alternância. Nesse sentido, as instituições de ensino devem buscar ferramentas que contribuam na superação do trabalho individual e isolado das disciplinas, presentes na organização curricular. Os aspectos da interdisciplinaridade, contextualização e formação por áreas de conhecimentos, defendidas na pedagogia da alternância, devem estar em constante movimento, garantindo a articulação dos saberes e uma formação, consideravelmente, mais crítica e questionadora dos educandos federalizados. Os princípios da alternância, por serem específicos de cada instituição, possibilitam flexibilização da organização curricular, processos de ensino-aprendizagem de educadores e educandos, além de projetos político-pedagógicos emancipadores. Tais princípios poderão nortear práticas pedagógicas que gerem aprendizagens significativas. Ciavatta (2005, p. 84) levanta as seguintes questões:

O que é integrar? É tornar íntegro, tornar inteiro, o quê. A palavra toma o sentido moral em alguns usos correntes. Mas não é disto que se trata aqui. Remetemos o termo ao seu sentido de completude, de compreensão das partes no seu todo ou da unidade no diverso, de tratar a educação como uma totalidade social, isto é, nas múltiplas mediações históricas que concretizam os processos educativos.

A formação técnica integrada aos instrumentos didático-pedagógicos da alternância, pode permitir à instituição, ofertas de cursos que considerem as especificidades dos estudantes. Neste caso específico, o curso técnico em agropecuária. Os projetos político-pedagógicos emancipadores, propostas curriculares e instrumentos 
didáticos devem valorizar as várias dimensões formativas e integral do ser humano, seus aspectos físico, intelectual, cultural e político. Importante ainda, se necessário, atentar para ampliação da carga horária total do curso, cumprindo as finalidades estabelecidas na educação profissional técnica e a integração dos instrumentos da alternância nos diversos campos de saberes. O ensino técnico federalizado, uma vez integrado aos instrumentos didático-pedagógicos da alternância, pode ir além da matriz curricular, promovendo a formação crítica e integral dos sujeitos. Para melhor compreensão Pacheco (2012, p. 58) afirma que:

A ideia de formação integrada sugere superar o ser humano dividido historicamente pela divisão social do trabalho entre a ação de executar e a ação de pensar, dirigir ou planejar. Trata-se de superar a redução da preparação para o trabalho ao seu aspecto operacional, simplificado, escoimado dos conhecimentos que estão na sua gênese científico-tecnológica e na sua apropriação histórico-social. Como formação humana, o que se busca é garantir ao adolescente, ao jovem e ao adulto trabalhador o direito a uma formação completa para a leitura do mundo e para a atuação como cidadão pertencente a um país, integrado dignamente a sua sociedade política.

A expansão das grandes cadeias produtivas, a competitividade no mercado e o aumento da produtividade exigem que educadores/as desempenhem suas funções com criticidade, autonomia e formação qualificada, considerando a diversidade e as transformações ocorridas no mundo do trabalho e na formação do trabalhador. É possível garantir tal formação através dos instrumentos didático-pedagógicos da alternância, articulada ao processo de humanização dos sujeitos, valorização dos saberes e olhares sobre a realidade social vigente. À educação não cabe uma visão reducionista, atuando, exclusivamente, como provedora no atendimento às demandas do mercado de trabalho. Nessa conjuntura, é extremante necessário romper com visões ingênuas de organização curricular. Segundo Sacristán (2000, p. 22):

[...] o currículo faz parte, na realidade, de múltiplos tipos de práticas que não podem reduzir-se unicamente à prática pedagógica de ensino; ações que são de ordem política, administrativa, de supervisão, de produção de meios, de criação intelectual, de avaliação, etc., e que, enquanto são subsistemas em parte autônomos e em parte interdependentes, geram forças diversas que incidem na ação pedagógica. Âmbitos que envolvem historicamente, de um sistema político e social a outro, de um sistema educativo a outro diferente. Todos esses usos geram mecanismos de decisão, tradições, crenças, conceitualizações, etc. que, de uma forma mais ou menos coerente, vão penetrando nos usos pedagógicos e podem ser apreciados com maior clareza em momentos de mudança. 
Nesse contexto, vislumbramos a possibilidade de colaboração na reorganização curricular do curso técnico em agropecuária, considerando os seguintes aspectos: as constantes e profundas transformações no mundo do trabalho exigem que educadores, educandos, familiares e comunidade desenvolvam estudos e pesquisas que valorizem as atividades produtivas, geração de renda, formação emancipadora, pedagogia da alternância e sua relação com os movimentos sociais e a educação do campo, nos diversos contextos socioeconômicos de produção dos saberes. Segundo Silva e Menezes (1999, p. 150) a respeito do currículo:

[...] tem significados que vão muito além daqueles aos quais as teorias tradicionais nos confinaram. O currículo é lugar, espaço, território. O currículo é relação de poder. O currículo é trajetória, viagem, percurso. O currículo é autobiografia, nossa vida, curriculum vitae: no currículo se forja nossa identidade. O currículo é texto, discurso, documento. O currículo é documento de identidade.

O curso técnico em agropecuária pode, na consolidação da sua organização curricular, contemplar a sustentabilidade do planeta, o desenvolvimento local e cultural, com foco na equidade socioeconômica. Incentivar que a educação profissional, na estreita relação, com os princípios da alternância, se articule com os diversos contextos produtivos, relações de trabalho, vocação produtiva, assim como, perfil socioeconômico e cultural de cada região. Necessário, ainda, consolidar ações que envolvam responsabilidade, cooperação, trabalho coletivo, subsistência familiar, humanização do trabalho, valorização das histórias de vida de educadores e educandos, formação por alternância, identidades e memórias. As políticas sociais de formação profissional devem estar, necessariamente, articuladas às políticas públicas de educação, desenvolvimento, emprego, trabalho e renda. É facultada à Instituição de Ensino a revisão dos cursos e currículos, considerando as orientações regulamentadoras do sistema de ensino. O artigo 39 da Lei de Diretrizes e Bases da Educação n. 9.394/96 afirma, em seu $\S 1$ o, que: "[...] Os cursos de educação profissional e tecnológica poderão ser organizados por eixos tecnológicos, possibilitando a construção de diferentes itinerários formativos, observadas as normas do respectivo sistema e nível de ensino" (BRASIL, 1996). Tais especificidades podem contribuir com a melhoria na qualidade de vida dos sujeitos e comunidades. Segundo Moreira e Silva (2011 , p. 35):

O currículo pode ser movimentado por intenções oficiais de transmissão de uma cultura oficial, mas o resultado nunca será o intencionado porque, precisamente, essa transmissão se dá em um contexto cultural de significação ativa dos materiais recebidos. A cultura e o cultural, nesse sentido, não estão tanto naquilo que se transmite quanto naquilo que se faz com o que se transmite. 
Entendemos que a expansão da educação profissional no Brasil e, com ela, a criação dos Institutos Federais, contribui para que os educandos tenham as condições necessárias de estudos, consolidando identidades profissionais e formação continuada, nos diversos cursos de nível médio e ensino superior, oferecidos pelos Institutos Federais. Saviani (1996) afirma a existência de cinco categorias do saber, essenciais para todo professor, devendo integrar todo processo de formação: saber atitudinal, saber crítico-contextual, saber específico, saber pedagógico e saber didático curricular. Acreditamos que tais categorias podem contribuir com a instrumentalização do ensino, a partir da pedagogia da alternância.

Nesse sentido, o curso técnico em agropecuária pode delimitar seu perfil profissional, habilitações e qualificação. A legislação em vigor aponta necessidade de identificar perfis requeridos pelo mundo do trabalho, formação humana, utilidade para cidadãos e sociedade. Ou seja, a Instituição de Ensino, numa estreita articulação com educadores, educandos, familiares, comunidades, pesquisas sobre pedagogia da alternância, educação do campo, movimentos sociais, mercado de trabalho, entre outros aspectos, deve ser a base para construção da organização curricular que contemple diversos olhares, competências e atribuições funcionais.

Num contexto de profundas mudanças políticas, econômicas e sociais, cada vez mais rápidas, as instituições de ensino precisam atender as novas demandas, atualizando permanentemente seus cursos, planos de estudo e organização curricular. Ensinar pressupõe aceitação dos riscos, desafios e análise das experiências, no processo de ensino e aprendizagem; corpo docente com compromisso, responsabilidade, formação crítica, emancipadora e sensível às diversidades. Nessa perspectiva, o Parecer n. 16/99 propõe que:

[...] as habilitações correspondentes às diversas áreas profissionais, para que mantenham a necessária consistência, devem levar em conta as demandas locais e regionais, considerando, inclusive, a possibilidade de surgimento de novas áreas. [...] a nova legislação, ao possibilitar a organização curricular independente e flexível, abre perspectivas de maior agilidade por parte das escolas na proposição de cursos.

Na essência, o princípio de flexibilidade pretende ser uma forma de preservar a autonomia da instituição de ensino, incentivando a participação da comunidade na definição das propostas pedagógicas, planos de trabalho e efetivo envolvimento no processo de ensino e aprendizagem dos estudantes. Esta é uma forma de garantir que a escola permaneça atenta às novas demandas. Tal flexibilidade é verificada no artigo 4음 do Decreto Federal n. 5.154/04: 
[...] A educação profissional técnica de nível médio, nos termos dispostos no $\S$ $2^{\circ}$ do art. 36, art. 40 e parágrafo único do art. 41 da Lei nº 9.394, de 1996, será desenvolvida de forma articulada com o ensino médio, observados: III as exigências de cada instituição de ensino, nos termos de seu projeto pedagógico. (BRASIL, 2004a).

Nesse contexto, os projetos político-pedagógicos dos cursos de educação profissional devem, necessariamente, se articular com as políticas de desenvolvimento econômico, local, regional, nacional e com os sistemas públicos de emprego, trabaIho e renda. Tais aspectos fortalecem as expectativas de melhoria na qualidade de vida, indispensáveis à realização da cidadania ativa. O Parecer CNE/CEB n. 39/2004, orienta que:

[...] para oferta dos cursos de Educação Profissional Técnica de nível médio os critérios são os seguintes: • o atendimento às demandas dos cidadãos, da sociedade e do mundo do trabalho, em sintonia com as exigências do desenvolvimento socioeconômico local, regional e nacional; • a conciliação das demandas identificadas com a vocação da instituição de ensino e as suas reais condições de viabilização das propostas; • a identificação de perfis profissionais próprios para cada curso, em função das demandas identificadas e em sintonia com as políticas de promoção do desenvolvimento sustentável do país; • a organização curricular dos cursos de técnico de nível médio, por áreas profissionais, em função da estrutura sócio-ocupacional e tecnológica. (BRASIL, 2004b).

O Decreto n. 5.840/2006, em seu artigo 5으, estabelece que:

[...] as instituições de ensino ofertantes de cursos e programas do Proeja serão responsáveis pela estruturação dos cursos oferecidos e pela expedição de certificados e diplomas. Parágrafo único. As áreas profissionais escolhidas para a estruturação dos cursos serão, preferencialmente, as que maior sintonia guardarem com as demandas de nível local e regional, de forma a contribuir com o fortalecimento das estratégias de desenvolvimento socioeconômico e cultural. (BRASIL, 2006).

A instituição de ensino, na implantação / reorganização do seu curso, deve observar o Catálogo Nacional de Cursos Técnicos de Nível Médio, implementado através da Resolução n. 3/2008 . Esse é um documento de referência para oferta dos cursos técnicos, de nível médio, nos diferentes sistemas de ensino do país. Tem como finalidade instrumentalizar a oferta de tais cursos e as denominações empregadas. 0 Catálogo proposto foi estruturado a partir de eixos tecnológicos, que reorganizam o quadro das áreas profissionais, em vigor. No momento conta com 155 denominações de cursos técnicos, em nível médio. O artigo 8o da Resolução n. 3/2008, descreve que: 
[...] as adequações procedidas pela instituição de Educação Profissional e Tecnológica poderão ser implantadas [...] mediante consulta documentada à comunidade escolar, devendo, neste caso, eventuais distorções serem corrigidas a posteriori pela respectiva instituição de ensino, segundo orientação dos órgãos próprios do respectivo sistema de ensino.

Assim, temos uma diversidade de cursos de educação profissional que podem ser ofertados nas diversas regiões do país. No Parecer n. 11/2008, constatamos que: "[...] para cada curso há uma breve descrição contendo: atividades do perfil profissional; possibilidades de temas a serem abordados na formação; possibilidades de atuação; infraestrutura recomendada; além da indicação da carga horária mínima" (BRASIL, 2008). Essa sugestão dá entender que existem possibilidades para melhorar a organização das propostas pedagógicas, planos de trabalho e cursos nas instituições de ensino, considerando as questões atuais. Em nosso caso, prevalece os debates acerca das possíveis interfaces entre educação profissional, curso técnico em agropecuária, instrumentos didáticos e pedagógicos da alternância, educação do campo e movimentos sociais.

\section{CONSIDERAÇÕES FINAIS}

São reais as possibilidades políticas, pedagógicas e sociais, nas instituições de ensino, para o desenvolvimento de projetos de cursos técnicos, definidos a partir dos resultados de pesquisas, articuladas com a comunidade e de acordo com os arranjos produtivos locais (APLS). Em consonância, inclusive, com o atual catálogo nacional de cursos técnicos, explicitamente favorável à flexibilidade da produção do conhecimento e, de alguma forma, percebidos na organização curricular e Projeto Político do Curso Técnico (PPC) em Agropecuária, no Instituto Federal do Espírito Santo (IFES), Campus Barra de São Francisco.

Quero salientar que a produção do conhecimento pautada nos dados coletados e nas observações efetuadas não são isentas de valores. A construção crítica e coerente do saber não é neutra. Assim, a história pessoal dos autores permeou todo o desenvolvimento desse trabalho. Esperamos, dessa forma, estimular a produção de leituras e reflexões que contemplem a formação dos sujeitos do campo. Nesse processo de construção histórica, prevaleceu o respeito às diferenças e a valorização da identidade cultural dos atores envolvidos, propondo uma educação inclusiva, questionadora e democrática, presente nas instituições de ensino federalizadas. 
Por fim, é importante novamente registrar a preocupação do IFES, Campus Barra de São Francisco, em especial, com os atores que fazem acontecer o Curso Técnico em Agropecuária, suas contribuições, direta e indireta, na formação dos sujeitos do campo. Sugiro aos leitores a continuidade desses estudos, com o objetivo de compreender a estratégica relevância e as possíveis interfaces entre os instrumentos didáticos e pedagógicos da alternância, os movimentos sociais e a educação profissional.

\section{REFERÊNCIAS}

BEGNAMI, João B. Formação pedagógica de monitores das Escolas Famílias Agrícolas e alternâncias: um estudo intensivo dos processos formativos de cinco monitores. 2003. Dissertação (Mestrado em Ciências da Educação) - Universidade Nova de Lisboa, Belo Horizonte, MG, 2003.

BRASIL. Ministério da Educação e Cultura. PRONACAMPO - Programa Nacional de Educação do Campo, lançado no dia 20 de março de 2012. Disponível em: <http://portal.mec. gov.br/pet/194-secretarias-112877938/secad-educacao-continuada-223369541/18720-pronacampo>.

. Ministério da Educação e Cultura. Resolução n. 4, de 13 de julho de 2010. Define as Diretrizes Curriculares Nacionais Gerais para a Educação Básica e, nela, a educação do campo como modalidade de ensino. Disponível em: <http://portal.mec.gov.br/dmdocuments/ rceb004_10.pdf>.

. Ministério da Educação e Cultura. Decreto n. 7.352, de 4 de novembro de 2010. Dispõe sobre a política de educação do campo e o Programa Nacional de Educação na Reforma Agrária - PRONERA. Disponível em: <http://portal.mec.gov.br/docman/marco-2012-pdf/10199-8-decreto-7352-de4-de-novembro-de-2010/file>.

. Ministério da Educação e Cultura. Parecer n. 11/08, de 12 de junho de 2008. Disponível em: <http://portal.mec.gov.br/cne/arquivos/pdf/2008/pceb011_08.pdf>. Acesso em: 4 out. 2014.

. Decreto n. 5.840, de 13 de julho de 2006. Disponível em: <http://www.planalto.gov. br/ccivil_03/_ato2004-2006/2006/decreto/d5840.htm>. Acesso em: 4 out. 2014.

. Decreto n. 5.154/04, de 23 de julho de 2004a. Disponível em: <http://www.planalto.

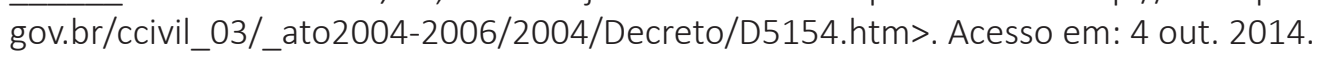

. Ministério da Educação e Cultura. Parecer n. 39/04, de 8 de dezembro de 2004b. Disponível em: <http://portal.mec.gov.br/setec/arquivos/pdf_legislacao/tecnico/legisla_tecnico_parecer392004.pdf>. Acesso em: 4 out. 2014.

. Decreto n. 2.208, de 17 de abril de 1997. Regulamenta o § 20 do art. 36 e os arts. 39 a 42 da Lei n. 9.394, de 20 de dezembro de 1996, que estabelece as diretrizes e bases da educação nacional. Disponível em: <http://www.camara.gov.br/sileg/integras/254359.pdf>. 
. Resolução n. 3, de 9 de julho de 2008. Dispõe sobre a instituição e implantação do Catálogo Nacional de Cursos Técnicos de Nível Médio. Disponível em: <http://portal.mec. gov.br/setec/arquivos/pdf/rceb003_08.pdf.

. Ministério da Educação e Cultura. Conselho Nacional de Educação / Conselho Educação Básica. Resolução CNE/CEB n. 1, de 3 de abril de 2002. Diretrizes Operacionais para a Educação Básica das Escolas do Campo. Disponível em: <http://portal.mec.gov.br/ index.php?option=com_docman\&view=download\&alias=13800-rceb001-02-pdf\&category_ slug=agosto-2013-pdf\&ltemid=30192> .

. Ministério da Educação e Cultura. Parecer CNE/CEB n. 16/99, de 5 de outubro de 1999. Disponível em: <http://portal.mec.gov.br/setec/arquivos/pdf_legislacao/tecnico/ legisla_tecnico_parecer1699.pdf>. Acesso em: 4 out. 2014.

. Lei n. 9.394/96, de 20 de dezembro de 1996. Lei de Diretrizes e Bases da Educação Nacional. Brasília: MEC/SEF, 1996.

. Constituição da República Federativa do Brasil. 1988. Disponível em: <http://www. planalto.gov.br/ccivil_03/constituicao/constituicao.htm>.

. Lei 4024/61. Dispõe sobre as diretrizes e bases da educação nacional. Diário Oficial. Brasília, 20 de dezembro de 1961.

CIAVATTA, Maria (Org.). Ensino Médio Integrado: concepção e contradições. 1. ed. São Paulo: Cortez, 2005.

FRIGOTTO, Gaudêncio. Fundamentos da educação escolar do Brasil contemporâneo. Entrevista concedida a Fernanda Buarque de Hollanda, em 10/08/2006. Disponível em: $<$ https://agencia.fiocruz.br/frigotto-aborda-o-livro-fundamentos-da-educa\%C3\%A7\%C3\% A3o-escolar-do-brasil-contempor\%C3\%A2neo>. Acesso em: 6 out. 2014.

GIMONET, J. C. Praticar e compreender a pedagogia dos CEFFAs. Petrópolis, RJ: Vozes, 2007. MOREIRA, Antonio Flávio; SILVA, Tomaz Tadeu da. Cultura, currículo e sociedade. São Paulo: Cortez, 2011.

PACHECO, Eliezer (Org.). Perspectivas da educação profissional de nível médio: proposta de diretrizes curriculares. São Paulo: Fundação Santillana; Moderna, 2012.

SACRISTÁN, J. Gimeno. O currículo: uma reflexão sobre a prática. 3. ed. Porto Alegre: Artmed, 2000.

SAVIANI, D. Pedagogia histórico-crítica: primeiras aproximações. Campinas, SP: Editores Autores Associados, 1996.

SILVA, Edna Lúcia da; MENEZES, Estera Muszkat. Metodologia da pesquisa e elaboração de dissertação. 3. ed. rev. e atual. Florianópolis: Laboratório de Ensino a Distancia da UFSC, 1999.

SILVA, Lourdes Helena. Modalidades, representações e práticas de alternância na formação de jovens agricultores. Revista da Formação por Alternância, Brasília, v. 1, n. 2, p. 5-23, 2006. 


\section{Sobre os autores:}

Ramofly Bicalho: Docente na UFRRJ - Universidade Federal Rural do Rio de Janeiro, Campus Seropédica. Lotado no Departamento de Educação do Campo, Movimentos Sociais e Diversidade. Docente na Licenciatura em Educação do Campo, no PPGEA - Programa de Pós-Graduação em Educação Agrícola e no PPGEduc - Programa de Pós-Graduação em Educação, Contextos Contemporâneos e Demandas Populares. Pós-Doutorado em Educação na Universidade Federal Fluminense - UFF. Atua com as seguintes temáticas: História da Educação do Campo e os Movimentos Sociais. Educação Popular e Educação de Jovens e Adultos. E-mail: ramofly@gmail.com

Jean Rubyo Oliveira: Mestre em Educação Agrícola pela Universidade Federal Rural do Rio de Janeiro. Diretor do Instituto Federal do Espírito Santo (IFES), Campus Barra de São Francisco, ES. E-mail: jeanrubyo@ifes.edu.br

\section{Recebido em maio de 2016}

Aprovado para publicação em julho de 2017 